\title{
The Financial Risks of Internet Merger and Acquisition under the Internet Ecology Circle and the Countermeasures
}

\author{
Jinyu Tian \\ Department of Economics and Management, North China \\ Electric Power University \\ Baoding, Hebei Province, China
}

\author{
Shiyao Wang \\ Department of Economics and Management, North China \\ Electric Power University \\ Baoding, Hebei Province, China \\ wsynet@126.com
}

\begin{abstract}
With the development of the Internet industry, more and more Internet companies realize that they cannot develop stably in the future market only by their own development. Only by cooperating with other enterprises can they have real strength in the long-term development. Especially in the development of the Internet matures today, more and more enterprises start $M \& A$ (Mergers and acquisitions) activity to build the Internet industry advantages of the ecosystem. In this condition, if the Internet companies cannot identify the risks of mergers and acquisitions, carry $M$ \& $A$ activities blindly, the future development will still be difficult. This paper focuses on analyzing the current situation of $M \& A$ in the construction of Internet ecosystem, and tries to analyze the financial risks. Combining the current situation of Internet $M \& A$, the paper analyzes the financial risks that should be paid attention to and gives suggestions on corresponding measures when enterprises are faced with financial risks in financing and payment.
\end{abstract}

Keywords-Internet ecosystem; Internet enterprise; M \& A; Financial risk

\section{INTRODUCTION}

In recent years, the development of the Internet is far more than imagination. When the public opinion in the taxi, travel, take-away, online shopping overseas, etc. just go on the Internet road industry "cash burning", many companies have shifted secretly from competition to mergers and acquisitions. As the traditional enterprises in the "Internet + " trend have tilted to the Internet, the Internet companies in the future is to be able to occupy the voice of the Internet ecosystem in the future, to $\mathrm{M} \& \mathrm{~A}$ as a means of distribution, quickly decided in various industries and fields A series of $\mathrm{M} \& \mathrm{~A}$ activities.

\section{RELATED THEORETICAL BASIS}

\section{A. The Internet ecosystem}

"Internet ecosystem", was put forward the earliest by the YALI Science and Technology Wu Jinjun in August 8, 2015. $\mathrm{Wu}$ defined the Internet ecosystem as "using the Internet to improve the ecological business." He believes that all the Internet-related elements within the enterprise belong to the Internet ecosystem, including enterprise PC Internet sites, mobile smart sites, mobile APP, WeChat platform, OA office systems, terminal intelligent interactive machine, background data and online Internet training And so on. These modules constitute a complete, benign, and effective enterprise Internet ecosystem.

\section{B. Financial risks}

Financial risk, mainly refers to the enterprise in the process of mergers and acquisitions, due to mergers and acquisitions pricing, financing, payment and follow-up integration caused by the decision-making, resulting in loss of solvency of the company's ability to lead to investors expected earnings decline, triggering enterprise financial crisis possibility. Financial risk is a real problem that enterprises must face in the process of financial management, especially in the $M \& A$ activities of enterprises, financial risk exists objectively and is continuous. The managers only can take effective measures to reduce risk, but cannot completely eliminate the risk. ${ }^{[1]}$ Similar to other industries, the internet industry is along with the Internet industry mergers and acquisitions from the financial risks, mainly from the merger of enterprises in equity, debt conversion. Therefore, the financial risk of Internet M \& A can be divided into narrow financial risk and broad financial risk.

In the narrow sense, the financial risk mainly refers to the increase of the market value of the enterprise due to the failure of the $M \& A$, the decrease of the market value and the rising of the management cost, mainly due to mergers and acquisitions financing on the solvency of enterprises and shareholders of interest arising from the impact of the outflow of interest. Financial risk in a broad sense refers to the enterprise in the daily management activities, due to uncertainties caused by the actual interests of enterprises, and ultimately leads to the possibility of increasing profits or losses. [2] Internet industry characteristics determine that their own financial risks in mergers and acquisitions are unique. Internet companies in an invisible platform for the development of instability, themselves have some potential risks. As an investment interaction of enterprise to expand their business, merger and acquisition involve in mergers and acquisitions costs, debt, equity and many other aspects. Financial risk will also extend from the merger before the merger activities to an end or even longer period of time. 
PRESS

\section{ANALYSIS OF INTERNET M \& A STATUS IN THE INTERNET ECOSPHERE}

\section{A. The status of Internet $M \& A$}

Since the late 90 s of last century Internet enterprise mergers and acquisitions began and then never stop steps. However, because the Internet has not yet formed a mature and stable ecological environment, $\mathrm{M} \& \mathrm{~A}$ activity is mainly concentrated in the early start of the foreign Internet companies. Although many enterprises have carried out $\mathrm{M} \& \mathrm{~A}$ activities, the real problem has not been resolved. Internet technology in recent years to enhance and expand the audience makes the Internet mergers and acquisitions tide again warming. In 2005, Ebay merged Skype and Facebook completed Instagram Acquisition in 2012. They are illustrated in the optimization of the Internet environment for the needs of enterprises. ${ }^{[3]}$ Over time, Internet development hotspot has turned to China to BAT (Baidu, Alibaba, Tencent) as the representative of the new Internet industry structure has been established. Internet ecosystem development trend, the Internet business $M$ \& A activities come and go, more and more enterprises reflect the layout of "from the chain to the circle" in the Internet ecosystem to seek market and status determination. China's Internet giant, represented by three Internet giants, has been involved in many industries, such as e-commerce, finance, tourism, transportation and medical treatment, and has achieved remarkable results.

In 2013, Baidu search engine as the core business, carrys mergers and acquisitions 91 wireless, glutinous rice network, PPS and other investment, to achieve the rapid growth of stock prices. After the catering industry tends to Nuo Mi, it develops Baidu wallet, trying to get into the field of fast payment; from 2015 to now, Baidu has layout in medical and football, first to "connect the patient + artificial intelligence" as the main line integration of "medical + drugs", opened eight medical plates. And there is rumors of the acquisition of AC Milan, and this actively conforms to the state on the "overall reform and development of Chinese football program," the measures, the development momentum significantly. Tencent also has WeChat and QQ two communication tools, in the microbusiness, micro-payment to pay the rapid development, after trying to spare no effort in e-commerce articles, and mergers and acquisitions began to overseas development, successive mergers and acquisitions of nine overseas game companies; In April 2016 a source pointed out that Tencent is negotiating with the bank, hoping to get $\$ 2$ billion in bank loans for the acquisition of expansion. Alibaba has access to Sina microblogging, UC, high German map and a number of logistics company's shares; In 2014, Alibaba Hengda signed; in April 2016, based on the announced merger plan in November 6, 2015, it completes Group (Youku potatoes) of the merger transaction, so that Youku potatoes officially became its wholly-owned subsidiary; current by the Alibaba's Ant Financial Services Group to set up the "ants gold service" business has covered in addition to deposits outside the loan, Financial, insurance and other traditional financial institutions business.

\section{B. The Internet ecosystem under the existence of Internet $M$ \& A financial risk}

The financial activities of the whole $\mathrm{M} \& \mathrm{~A}$ process include the feasibility analysis of $M$ \& $A$, target enterprise value assessment, payment method selection, acquisition financing, post-acquisition integration and debt repayment. All of the above links may produce certain financial risks. But from the point of view of capital flow, the most closely related are enterprise value evaluation, financing and payment strategy. These aspects determine the financial initial arrangement, such as the object, amount and payment method of capital and financing, and decide later financial the situation, all aspects of mutual influence, mutual restraint, together constitute the M \& A process of financial risk. ${ }^{[4]}$ The main motive of the current Internet business mergers in addition to strong mergers between the increases in strength, the more is to cope with the conditions of development of the Internet companies because of their own development of the unity of the industry made to move towards diversification.

Internet companies are generally functioning with strong profitability, low debt, solvency, weak collection capacity, cash liquidity, weak operating capacity. In this case, enterprises in a field because of short board, and other businesses must have the advantage of the merger has reached a win-win cooperation to achieve "1 $+1>2$ " effect, for the formation of Internet ecosystem ready. But this will lead to the corresponding financial risks; can be divided into the following two parts:

\section{1) Valuation risk}

Most of the Internet products and services are carried out on the network, in order to maintain the market advantage of products and services, enterprise development requires both packaging and technology. At this point, the importance of physical products compared to the internal strife instead of online, enterprises eventually enter the market by consumers and the market first accepted may no longer be tangible products and services, but intangible assets. ${ }^{[5]}$ Therefore, when assessing the acquired companies, due to the lack of precise valuation methods of intangible assets such as online products and services, the evaluation value of intangible assets in the process of actual evaluation is difficult to be determined which affects the enterprises the determination of value.

\section{2) Financing and payment risks}

Some Internet companies as a result of a more concentrated large-scale investment $M$ \& A activities, resulting in their own financial risk increased rapidly. In the period of large-scale financing, the company's asset-liability ratio is rising all the way. At this time, the enterprise faces certain financing and payment risks, and needs to choose financing and payment according to their own situation.

\section{INTERNET CORPORATE MERGERS AND ACQUISITIONS IN THE FINANCIAL RISK CONTROL MEASURES}

Financial risk control mainly refers to the financial management process, the use of relevant information and specific means of corporate financial activities to influence or adjust in order to achieve the financial objectives set by the plan, to maximize risk aversion. In the Internet $M$ \& $A$ activities, enterprises should pay attention to control financial 
risks, including prevention and control valuations, choose the right way of payment and financing. In addition, we should learn from the mode of operation of domestic and foreign enterprises, the right to judge the $\mathrm{M} \& \mathrm{~A}$ needs, not blind $\mathrm{M} \&$ A activities.

First, do good jobs in the pre-valuation survey works. The preliminary investigation mainly includes the legitimacy investigation, the fact investigation, and the development prospect investigation. The enterprise shall verify the authenticity and legitimacy of the financial statements and nonreporting items, and determine the potential risks. Based on the reasonable estimation, the enterprise shall investigate the investigation and development prospect of the project net cash flow, static investment recovery period and dynamic payback period.

The second is to choose a reasonable method of valuation. Should be clear first Internet companies and traditional enterprises of different, for example, the traditional mobile phone sales brands such as Amoi, HTC, and through Internet marketing to create millet, Meizu, Smartisan, music as compared to the valuation results may be far. Profitability, market share, talent, technology and so on, but also to analyze the financial, including the assets, including financial assets, financial and other aspects of the target enterprise, liabilities, and taxes on the content. The aim is to narrow the gap between the valuation price and the firm's real value. ${ }^{[6]}$

Third, make the right choice of payment and financing. Enterprises should fully understand the advantages and disadvantages of various payment methods and financing methods, combined with the actual situation of the company to choose the appropriate way to low capital, low risk as the fundamental purpose, according to the enterprise cash flow, solvency, Debt repayment period, credit, loan amount, corporate finance period and other realistic conditions, a reasonable choice of payment and financing. In order to meet the daily operations of enterprises at the same time to achieve the purpose of mergers and acquisitions, to achieve the enterprise's financial and operational objectives.

Fourth, learn from domestic and foreign experience, not blindly reached a merger agreement. At present, the $M$ \& A activities of the two ideas, one is based on industry development, powerful combination of similar business content; the other is the integration of traditional enterprises and Internet companies around the main chain of companies to explore the depth of the upstream and downstream, a horizontal, A vertical, are for the construction of the Internet ecosystem and development. However, mergers and acquisitions are not omnipotent, in the face of different stages of economic development, corporate $M$ \& A activities should be rational analysis of their strengths and weaknesses, to determine whether the need for mergers and acquisitions, what kind of enterprise mergers and acquisitions and whether the original Economic development in the advantage or advantage is more obvious.

\section{CONCLUSION}

In future, with the Internet development environment more mature and stable and the laws and regulations more standardized and sound, more and more Internet companies will integrate more industries, more enterprises to participate in business activities to achieve the development goals, or to pursue some interests of the enterprise demands, or to follow the development trend of the times. To ensure the smooth layout of the Internet ecosystem, enterprises should learn from domestic and international M \& A experience in all walks of life to understand the pre-merger economic environment and the possible impact of mergers and acquisitions, select a reasonable valuation method for the target enterprise valuation, to determine its true value, thus $M \& A$ activities. Mergers and acquisitions in the company's early, for the upcoming M \& A activities should be done in advance sufficient market research and rational financing programs, planning programs, not blind mergers and acquisitions to ensure that the $M$ \& A process transparent and smooth, to ensure that enterprises at least after the merger will not Mergers and acquisitions caused huge losses. Mergers and acquisitions in the effective avoidance of financial risks can enable enterprises to ensure that their interests are not infringed, while $M$ \& A activities to maximize the interests and minimize the risk, so as to prepare for the future development of enterprises pave the way. Online and offline, the effective integration of related resources, can make the Internet companies gradually explore their core competitiveness, to seek a breakthrough. Internet companies can not only affect a variety of products and services on the Internet, but also use the Internet under the same line of traditional industries to integrate, to "convey" updated products and services to society, so that all walks of life can be revitalized.

\section{REFERENCES}

[1] Hua Kui. Financial Risk Control of Mergers and Acquisitions Based on Transaction and Integration - Case Study of China Eastern Airlines Merger and Acquisition (SAE) [D]. East China University of Science and Technology, 2014. (In Chinese)

[2] Deng Qianni. Research on the Financial Risk of M \& A of Hundsun Technologies Inc. [D], Liaoning University, 2015. (In Chinese)

[3] Sun Huimin. Internet $M \& A$ risk identification and control [D]. Inner Mongolia University, 2014. (In Chinese)

[4] Yang Liu, Wu Sizong, Tong Aiqin. An Empirical Study on Financial Risks of Cross-border M \& A in China's Manufacturing Industry $[\mathrm{J}]$.Communication of Finance and Accounting, 2009, 30: 110-112+123. (In Chinese)

[5] Li Yilin, Chen Sidong. Risk and Control of Internet M \& A [J] .Manager Journal, 2015, 17: 173- 174. (In Chinese)

[6] Pan Le-yuan. Based on Internet M \& A financial integration risk and measures analysis [J]. Finance and Economics (Academic Edition), 2015,03: $163+268$ (In Chinese) 